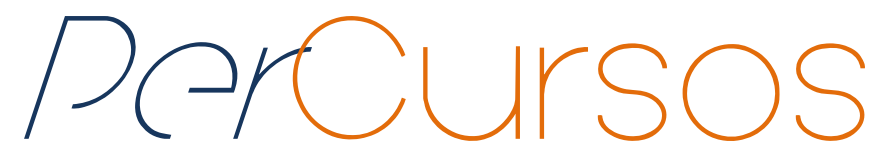

\title{
Mapeamento digital das áreas propícias às enchentes e inundações na bacia do Córrego do Lenheiro em São João del- Rei - MG
}

\begin{abstract}
Resumo
O termo "desastres humanos de natureza" refere-se aos desastres provocados pela influência antrópica e, no Brasil, os mais recorrentes são as inundações em áreas urbanas. Neste artigo, objetiva-se indicar as ações humanas que ocasionam enchentes e inundações na área urbana localizada na Bacia do Córrego do Lenheiro, no município de São João del-Rei - MG. A fundamentação teórica e metodológica tem como base a Teoria Geral dos Sistemas Aplicados à Geografia. Uma base cartográfica e um modelo de síntese das áreas suscetíveis aos desastres humanos de natureza foram elaborados no software ArcGis10.1®. Dados primários foram coletados em campo, por meio de observações, registros fotográficos e aplicação de um questionário respondido por 24 moradores. Aliado a estes, foram analisados dados secundários coletados em órgãos públicos. Os resultados e análises indicam que as ações antrópicas intensificam a elevação temporária do nível das águas nos canais fluviais e resultam em enchentes. As inundações atingem a população devido à informalidade no processo de ocupação das áreas onde o Córrego do Lenheiro escoa sua capacidade máxima, extrapolando o limite do canal fluvial. Os dados primários indicam a ausência de informação dos moradores em relação aos riscos iminentes na área.
\end{abstract}

Palavras-chave: Áreas de Risco. Álgebra de Mapas. Cartografia Digital.
Thiago Gonçalves Santos

Graduando em Geografia pela Universidade Federal de São

João del-Rei - UFSJ.

Brasil

thiiaguim.13@gmail.com

\section{Sílvia Elena Ventorini}

Doutora em Geografia pela Universidade Estadual Paulista Júlio de Mesquita Filho - UNESP. Brasil

sventorini.@ufsj.edu.br

\section{Para citar este artigo:}

SANTOS, Thiago Gonçalves; VENTORINI, Sílvia Elena. Mapeamento digital das áreas propícias às enchentes e inundações na bacia do Córrego do Lenheiro em São João del-Rei - MG. Revista PerCursos, Florianópolis, v. 18, n.36, p. 95 -124, jan./abr. 2017.

\section{DOI: $10.5965 / 1984724618362017095$}

http://dx.doi.org/10.5965/1984724618362017095 


\title{
Digital mapping of reas propitious to floods and inundations on Lenheiro's stream basin in São João del- Rei - MG
}

\begin{abstract}
The term human-made environmental hazards refers to disasters caused by anthropic influence and, in Brazil, the most common are the inundations in urban areas. The objective of this article is to indicate the human actions that cause floods and inundations in the urban area located on Lenheiro's stream basin, in the city of São João del-Rei - MG. The theoretical and methodological framework is based on Systems Theory applied to geography. A basemap and a model synthesis of the areas susceptible to human-made environmental hazards were elaborated with the ArcGis 10.1 $\mathrm{R}$ software. Primary data were collected in field by means of observation, photographic registers, and a questionnaire answered by 24 residents. Along with these, secondary data collected in public bodies were used. The results and the analyses indicate that the anthropic actions intensify the temporary elevation of the water in fluvial channels and result in floods. The inundations reach the population due to the informality in the process of occupation of the areas where Lenheiro's stream overflows its maximum capacity, extrapolating the fluvial channel's limit. The primary data indicate the absence of information related to the imminent risks in the area among the residents.
\end{abstract}

Keywords: Risk Areas. Map Algebra. Digital Mapping.. 


\section{Introdução}

O termo "desastre", neste trabalho, refere-se aos desastres de origem natural, independente das ações antrópicas, e aos desastres intensificados pela ação e/ou omissão do homem (CODAR, 1995; CASTRO, 1998; TOMINAGA, 2009). Os prejuízos econômicos e sociais ocasionados por esses desastres estão se intensificando no cotidiano das pessoas. Tal fato é resultante do crescimento das cidades que concentram população e atividades que modificam a estabilidade natural dos locais e resultam em:

[...] calamidades engendradas por fenômenos próprios da dinâmica dos lugares, exacerbados por práticas socioambientais divorciadas das características físicas dos locais. $\mathrm{O}$ avanço das cidades acontece muitas vezes em direção aos ambientes frágeis como florestas, encostas e mananciais, e em muitas partes do mundo os novos assentamentos, que surgem rapidamente, de maneira caótica e fora dos padrões legais de regulamentação de uso, são cada vez mais distantes. Isso induz o deslocamento da população para locais onde possibilidades de emprego e acesso aos serviços de saúde, educação e lazer são maiores mas essa movimentação expõe mais pessoas ao risco de serem atingidas por desastres naturais, fenômenos que conjugam uma componente física, que é o elemento deflagrador (por exemplo, excesso ou deficiência de chuvas, ventos fortes, erupções vulcânicas) e uma social que diz respeito aos impactos na população humana, que é proporcional a sua vulnerabilidade. (NUNES, 2015, p. 182)

Nos centros urbanos, as consequências dos desastres são mais intensas, por causa da significativa concentração de pessoas, principalmente em áreas propícias às ocorrências de fenômenos naturais, como o caso das nações unidas sul-americanas (NUNES, 2015). Os desastres na América do Sul são classificados de acordo com as características geofísicas (terremotos e erupções vulcânicas), meteorológicas (tempestades), hidrológicas (enchentes, inundações, movimentos de massa), climatológicas (secas, incêndios) e biológicas (epidemias).

No Brasil, os desastres naturais são ocasionados por fenômenos da dinâmica externa da Terra, como inundações e enchentes, escorregamentos de massa, deslizamentos de vertentes e/ou rochas e tempestades. Esses fenômenos ocorrem, 
principalmente, no verão (regiões sul e sudeste) e no inverno (região nordeste), períodos em que os índices pluviométricos são intensos e prolongados (TOMINAGA, 2009).

Os dados publicados pela Emergency Events Database - EM-DAT - indicam que o Brasil está entre os países mais atingidos por desastres hidrológicos que ocasionam inundações, enchentes e deslizamentos. Tominga (2009) ressalta que, no ano de 2008, o Brasil esteve em $10^{\circ}$ lugar entre os países mais atingidos por esses desastres, cujo número de vítimas foi de 1,8 milhão. A análise dos dados da EM-DAT, entre o período de 1960 e 2013, indica que houve o registro de 119 desastres no Brasil que resultaram em 7.300 mortes, e em prejuízos econômicos para mais de 19 milhões de pessoas.

No entanto, uma análise comparativa entre os dados da EM-DAT e do Atlas Brasileiro de Desastres Naturais, para o período de 1991 a 2010, mostra significativas diferenças nos registros de ocorrências de desastres, de óbitos e de pessoas atingidas. Os dados disponibilizados no Atlas mostram registros de 31.909 desastres, 3.404 óbitos e 96.220.879 pessoas afetadas. Por outro lado, para o mesmo período, a EM-DAT registrou 103 desastres, 2.689 óbitos e 18.266.784 pessoas atingidas (CARMO; ANAZAWA, 2014). Essa diferença ocorre porque nos registros da EM-DAT somente são computados os desastres que resultem em dez ou mais óbitos, que gerem prejuízos para 100 ou mais pessoas, ou quando um órgão público emite declaração de situação de emergência e/ou pedido de auxílio internacional.

Na literatura científica, o termo "desastre” inclui ainda as classificações: desastre natural, desastre humano/desastre humano de natureza e desastre misto (NUNES, 2015). Os desastres naturais são produzidos por fenômenos da natureza e intensificados ou não pela atividade antrópica, e são iniciados por características regionais como vegetação, condições meteorológicas, topografia entre outros (TOMINAGA, 2009; NUNES, 2015). Os desastres humanos/desastres humanos de natureza referem-se aos desastres provocados pela ação e/ou omissão antrópica, como por exemplo, as enchentes e inundações (CODAR, 1995; CASTRO, 1998; KOBIYAMA et al., 2006). Para Castro (1998): 
[...] desastres humanos de natureza: 1 - tecnológica, quando são conseqüências indesejáveis do incremento demográfico das cidades, sem o desenvolvimento compatível da infra-estrutura urbana e dos serviços essenciais, resultando, também, de um desenvolvimento imediatista e sem preocupação com a segurança contra desastres. Dentre os desastres de natureza tecnológica, destacam-se aqueles relacionados com meios de transporte, com produtos perigosos, com incêndios e explosões em plantas industriais, parques, depósitos e outros. 2 - social, quando são conseqüência do relacionamento do homem com os ecossistemas urbanos e rurais ou de desequilíbrios nos inter-relacionamentos econômicos, políticos e culturais. Dentre os desastres de natureza social, destacam-se aqueles relacionados com o desemprego e a marginalização social, com a fome e a desnutrição, com o incremento da violência, com os menores abandonados, com o banditismo, o crime organizado e o tráfico descontrolado de drogas. 3 - biológica, quando são conseqüência do subdesenvolvimento, do pauperismo e da redução da eficiência dos serviços promotores da saúde pública. Dentre esses desastres, destacamse a pandemia da SIDA/AIDS, a malária, a cólera, o dengue e a tuberculose. (CASTRO, 1998, p. 9)

Já os desastres mistos são causados por fatores naturais e antrópicos, decorrentes das atividades humanas combinadas com os fenômenos naturais. Dentro desta definição, consideram-se desastres mistos a:

1 - geodinâmica terrestre externa, como as chuvas ácidas, o incremento da poluição do ar provocada por camadas de inversão térmica, efeito estufa e bolsões de redução da camada de ozônio; 2 - geodinâmica terrestre interna, como a desertificação, a salinização do solo e a sismicidade induzida. (CASTRO, 1998, p. 9)

Os desastres humanos de natureza são os que mais ocasionam danos à população brasileira. A interferência humana potencializa a ocorrência de fenômenos como o caso das enchentes e inundações. A enchente é definida como a elevação temporária das águas fluviais até seu limite máximo das margens plenas de um canal (FERNANDEZ, 2003).

A extrapolação das águas do canal fluvial para as áreas de várzea dos rios é definida como inundação (TUCCI, BERTONI, 2003; BRASIL, 2007; HORA, 2009; CEPED, 
2011; SANTOS, VENTORINI, ALMEIDA, 2016). Como exemplo desta interferência, citam-se as construções em áreas de várzea (CASTRO, 1998; KOBIYAMA et al., 2006).

A análise da ocorrência de desastres é obtida por meio de três elementos básicos: perigo (hazards), risco e vulnerabilidade (WISNER et al., 2003, UITTO, 1998, INTERNATIONAL STRATEGY FOR DISASTER REDUCTION, 2004, BRASIL, 2007; LINDELL, PRATER, PERRY, 2006). O termo perigo é definido como processo anterior ao risco, capaz de causar efeitos danosos à população, ou seja, gerar uma condição para a ocorrência de consequências que prejudiquem a população economicamente e/ou ocasionem a perda de vidas (CASTRO, 2000; TOMINAGA, 2009).

O termo "risco" refere-se à possível ocorrência de um fenômeno e sua intensificação por danos causados em uma determinada área, ou seja, quanto maior o grau de perda, maior o risco (BRASIL, 2007). Na literatura científica, o termo "risco", no contexto dos desastres naturais, abrange as noções de incerteza, exposição ao perigo, perda e prejuízos materiais, econômicos e humanos (PEIXOTO, RIO, 2005). Já "vulnerabilidade" corresponde ao grau de perda dentro de uma determinada área suscetível ${ }^{1}$ à ocorrência de algum fenômeno, seja de aspectos físicos, econômicos, sociais e ambientais (TOMINAGA, 2009).

Publicações de Zacharias (2007), Brasil (2007), Almeida e Ventorini (2014), dentre outras, ressaltam a importância do mapeamento e monitoramento das áreas suscetíveis a risco, a perigo e à vulnerabilidade, por meio de uma base digital de dados cartográficos e alfanuméricos. A utilização de diferentes variáveis permite ao planejador a modelagem de sistemas com objetivos específicos.

O monitoramento e gerenciamento de áreas de riscos são legitimados pela Lei 12.608, de 10 de Abril de 2012, que institui a Política Nacional de Proteção e Defesa Civil (PNPDEC). A mesma dispõe do Sistema Nacional de Proteção Civil (SINPDEC) e do Conselho Nacional de Proteção e Defesa Civil (CONPDEC), que criou um sistema de monitoramento e de informações sobre desastres. O art. $4^{\circ}$, do parágrafo IV, prevê a

\footnotetext{
1 O termo "área suscetível" ou "suscetibilidade" é definido como potencial para a ocorrência de algum fenômeno em uma determinada área, cujos resultados geram prejuízos econômicos e sociais às populações atingidas, como o caso dos Desastres Humanos de Natureza (SÃO PAULO, 2014).
} 
adoção de bacia hidrográfica como unidade de análise de desastres, como diretriz da PNPDEC.

$\mathrm{O}$ art. $7^{\circ}$, do parágrafo IV, determina identificação, mapeamento e realização de estudos em áreas vulneráveis e suscetíveis aos riscos de desastres naturais e/ou desastres humanos de natureza. O mapeamento digital é um instrumento importante de identificação e caracterização das áreas de riscos, e serve como subsídio ao planejamento ambiental e urbano, assim como ao apoio às propostas mitigadoras à redução de danos causados por desastres humanos de natureza. Os mapas digitais permitem a análise e as sobreposições das representações dos fenômenos, contribuindo para o diagnóstico das áreas vulneráveis aos riscos e aos perigos de enchentes e às inundações (ZACHARIAS, 2007; HORA, 2009; SANTOS, VENTORINI, ALMEIDA, 2016).

Os municípios brasileiros encontram dificuldades para elaborar e atualizar uma base digital de dados. As dificuldades são ocasionadas, muitas vezes, pela ausência de recursos humanos especializados em geoprocessamento e/ou base de dados digital não danificada e organizada em um banco de dados. Tais fatores dificultam ou até impedem que as prefeituras elaborem uma base cartográfica digital como apoio ao monitoramento dos riscos, perigos e vulnerabilidades de ocorrências de desastres de natureza humana.

Neste artigo, tomamos como exemplo dessa realidade o município de São João del-Rei, localizado em Minas Gerais. No município, a ausência de mapeamento específico dificulta a ação e a minimização dos prejuízos causados por enchentes e alagamentos. A Defesa Civil do município publicou, em 2013, o Plano de Contingência e Proteção e Defesa Civil (PCPDC). No documento, é apresentado um mapeamento precário, sem critérios técnicos e científicos, cujas áreas de riscos foram demarcadas em imagens e mapas retirados do Google Maps, por meio da função print screen, e tratados com um programa de desenho simples, como o Paint (disponibilizado pela Microsoft ${ }^{\circledR}$ ). A análise do PCPDC indica, ainda, que os mapas mostram somente as áreas com registros de ocorrências, e não áreas propícias às ocorrências.

Em 2015, O PCPDC elaborado pela Defesa Civil foi atualizado pelo Serviço Geológico do Brasil (CPRM) e pelo Departamento de Gestão Territorial (DEGET). Porém, o 
documento continua apresentando somente os locais com registros de ocorrências e a partir de delimitações em imagens do Google Maps. Esse fato é resultante da ausência de uma base digital de dados cartográficos do município. A ausência de documentos cartográficos que possibilitem a identificação de áreas suscetíveis aos Desastres Humanos de Natureza no município instigou o desenvolvimento da pesquisa relatada neste artigo, cujo objetivo principal foi elaborar mapeamento digital como apoio à identificação de áreas suscetíveis aos referidos Desastres na Bacia do Córrego do Lenheiro. Para elaborar o mapeamento, adotaram-se procedimentos metodológicos da Análise Multicritério; por isso, os diálogos com os autores direcionam-se para esse tema.

\section{Análise multicritério: mapeamento digital das áreas suscetíveis a enchentes e inundações}

As representações cartográficas das realidades naturais e antrópicas, capazes de subsidiar o planejamento e gestão, possuem origem secular. Desde a Antiguidade, as cidades são planejadas, como exemplo, têm-se as cidades de Roma e da Grécia Antigas. Esse planejamento alcançou maior expressão no período renascentista, consolidando-se na segunda metade do século XIX (ALMEIDA, 2007).

O avanço tecnológico permitiu a otimização dos produtos cartográficos e o surgimento de novas metodologias instigadas pela influência antrópica e de impactos ambientais, sociais e econômicos. Tais metodologias são capazes de analisar as representações da realidade, por meio de modelos espaciais que consideram os fatores como um sistema integrado, no qual todos os elementos possuem algumas influências nas situações e/ou fenômenos modelados (ALMEIDA, 2007; MOURA, 2007).

Modelos são implicações do mundo real. Um mapa geológico é um modelo simbólico, porque representa um aspecto físico real, tendo como base a Ciência Geológica (BONHAM-CARTER, 1994). Para Chorley e Hagget (1967), um modelo é a simplificação e generalização da estrutura da realidade e de seus fenômenos. Por serem aproximações subjetivas da realidade, na medida em que não incluem todas as características reais, há diferentes modelos, com diferentes probabilidades de contribuir 
para analisar causa/efeito de um fenômeno. O modelo será útil, se apresentar alta probabilidade de aplicação e uma ampla gama de condições em que parece adequado. Para Moura e Jankowski (2016), os modelos podem representar:

[...] uma teoria, uma lei, uma hipótese, uma ideia estruturada, um relacionamento, uma função, uma equação, a síntese de dados ou a descrição do mundo real". Como simplificações da realidade, os modelos têm como ponto importante a seleção dos aspectos mais relevantes. $O$ sistema é estudado com determinada finalidade, e tudo o que não afeta o objetivo definido deve ser eliminado. (MOURA e JANKOWSKI, 2016, p. 667)

Para as pesquisadoras, ao decidir o objetivo do modelo que será gerado, deve-se elencar os dados necessários para sua geração, isolando-os em planos de informação ou em camadas. Esse procedimento é realizado por um Sistema de Informação Geográfica (SIG). Os SIG são frequentemente usados como instrumento para compreensão, análise e gestão de dados digitais de territórios complexos, sendo capazes de integrar informações diversas, como uso do solo, declividade, pedologia, hipsometria etc. Aos SIG são incorporadas novas funções, com o objetivo de possibilitar ao usuário realizar e/ou aprofundar operações e análises como a análise multicritério (FIDALGO, 2003; CABRAL, 2012).

A análise multicritério pode ser definida como um método de apoio à tomada de decisão, baseado na análise de alternativas para a resolução de um determinado problema (FIDALGO, 2003, VALENTE, 2005; MOURA, 2007; CABRAL, 2012; ALBUQUERQUE, 2015).

Essa análise é utilizada pelos usuários do SIG, por ser um método integrado da análise espacial, e por possibilitar a construção de modelos descritivos ou preditivos de um território, em diferentes escalas e para diferentes aplicações. A ampla utilização entre os referidos usuários ocorre pela facilidade na integração dos dados, com base em análise com múltiplos critérios, e pela disponibilização de ferramentas nos softwares de geoprocessamento, que podem ser utilizadas para implantar as etapas do processo de 
análise espacial por combinação de variáveis. No entanto, a facilidade de uso da análise multicritério para geração de modelos que apoiem a tomada de decisões não significa que não se deva questionar o impacto das incertezas inerentes em dados utilizados na análise, que são uma parte integrante do método (MOURA; JANKOWSKI, 2016).

Para a elaboração de uma base de dados que permita utilizar a análise multicritério ${ }^{2}$, é necessário que os mapas em vetor sejam transformados para o formato matricial (raster) com a adoção do mesmo valor de pixel para todos os mapas (MOURA, 2007).

Grassi et Al. (2013), em seu estudo sobre o mapeamento da vulnerabilidade das inundações e deslizamentos de terra no Estado do Paraná, adotaram procedimentos para a referida análise. Primeiramente, os autores elaboraram uma série de mapas temáticos e adotaram pesos de acordo com cada importância da variável e com a somatória da importância dos mapas igual a 100\%. A fórmula utilizada pelos autores em relação às inundações é:

$$
\frac{V . I N U N D .=(35 * P S L)+(20 * D E)+(25 * G E O M)+(10 * U S O)+(6 * S O L)+(4 * P R V)}{100}
$$

Na qual:

USO - Uso do Solo e Cobertura Vegetal; DE - Declividades (graus); SOL - Solos; GEOM - Geomorfologia; PRV - Proximidade da Rede Viária (metros); PSL - Proximidade de superfícies líquidas (metros).

A adoção dos pesos é uma etapa que pode ser realizada com base na Análise Hierárquica de Pesos (AHP), proposta pelo Prof. Thomas Saaty, em 1978, na Universidade da Pensilvânia. A AHP auxilia o especialista na tomada de decisão e tem o objetivo de determinar a contribuição de cada variável dentro do foco de estudo (MOURA, 2007). O método da AHP é aplicado por meio de comparação de dois a dois dentro de cada um dos critérios apresentados na tabela I.

\footnotetext{
${ }^{2} \mathrm{O}$ conceito de multicritério refere-se à tomada de decisão, com o objetivo de investigar quesitos importantes na análise do pesquisador, na qual busca-se relacionar preferências entre as alternativas apresentadas sendo possível a modelagem das variáveis e apresentação de resultado final (ARROYO, 2002; MOURA, 2007; CAMPOS 2011).
} 
Tabela I - análise hierárquica de peso (AHP).

\begin{tabular}{|l|l|}
\hline \multicolumn{2}{|c|}{ Análise Hierárquica de Pesos (AHP) } \\
\hline Pesos & Definição \\
\hline 1 & Importância igual: Os dois fatores contribuem igualmente para o objetivo. \\
\hline 3 & Importância moderada: Um fator é ligeiramente mais importante que o outro. \\
\hline 5 & Importância essencial: Um fator é claramente mais importante que o outro. \\
\hline 7 & $\begin{array}{l}\text { Importância demonstrada: Um fator é fortemente favorecido e sua maior } \\
\text { relevância foi demonstrada na prática. }\end{array}$ \\
\hline 9 & $\begin{array}{l}\text { Importância extrema: A evidência que diferencia os fatores é da maior ordem } \\
\text { possível. }\end{array}$ \\
\hline $2,4,6,8$ & $\begin{array}{l}\text { Valores intermediários entre julgamentos: Possibilidade de compromissos } \\
\text { adicionais. }\end{array}$ \\
\hline
\end{tabular}

Fonte: Adaptado de STAAY (2008, p.86).

A elaboração do mapa de interesse é dada por meio da álgebra de mapas realizada por um Sistema de Informação Geográfica (SIG). Esse processo consiste em uma operação matemática de média ponderada, na qual se consideram os valores de influência de cada variável e os pesos atribuídos a cada uma de suas classes (MOURA, 2007).

O processo de formulação de legendas requer a atribuição de valores numéricos de maneira hierárquica, conforme citado. Essa etapa se expressa na padronização de escalas que permite a representação das variáveis de estudo de modo quantitativo, segundo a importância de cada avaliação (MOURA, 2007). Como exemplo, em uma escala de 1 a 10, tal variável possui a legenda com as seguintes classes: "alto", "médio a alto", “médio”, "médio a baixo”, "baixo” e "nulo”; consideram-se os valores numéricos "10", “7”, “5”,“3”, “1” e “o” respectivamente. Em síntese, essa padronização de escalas permite a compreensão e análise das legendas, conforme a AHP (MOURA, 2007).

Para o método de análise multicritério, ressalta-se a importância de ter um material cartográfico confiável: "La calidad del material cartográfico base y la forma de tratamiento de este material en un SIG también influirá de modo significativo el resultado 
final del análisis multicritério" (MAUS et. al, 2014, p. 4). Nesta pesquisa, durante a elaboração e análise dos mapas temáticos e do modelo síntese, foram analisadas e utilizadas as colocações abordadas pelos autores citados anteriormente, conforme descrito a seguir.

\section{Metodologia}

A fundamentação teórica tem como base a Teoria Geral dos Sistemas (TGS) aplicados à Geografia, proposta por Christofoletti (1979), que destaca a importância de trabalhos publicados em 1950 e 1952, por Straller, e ressalta que, embora estas publicações sejam as pioneiras, os usos da TGS em geografia física "começaram a se avolumar na década de 1960, servindo como ponto de partida o artigo de Chorley" (CHRISTOFOLETTI, 1990, p. 21).

A aplicação da TCS na geografia permite a análise integrada do meio ambiente e dos elementos que o compõem, capaz de gerar um modelo complexo no qual surge a necessidade de geração de modelos aptos à realização de análises e interpretação destas áreas (CHRISTOFOLETTI, 1979 AUMOND, LOCH, COMIN, 2012; SOUZA, CUNHA, 2012; TROPPMAIR, 2004, 2006; SANTOS, VENTORINI, ALMEIDA, 2016).

A abordagem sistêmica é amplamente utilizada e tem obtido resultados mais produtivos no que se refere às questões ambientais. Os estudos realizados envolvem a geração e análise de mapas; para isso, é necessária a definição do seu objeto de estudo, das características das variáveis estudadas e das relações entre as partes, modelando, assim, um sistema e ajustando-o frente à realidade (MOURA, 2003; SOUZA, CUNHA, 2012).

$\mathrm{Na}$ abordagem sistêmica aplicada aos estudos que envolvem geração e análise de mapas, faz-se necessário definir o que é mapeado, as variáveis que compõem esse mapeamento e suas análises, bem como as características dessas variáveis e as relações entre as partes, modelando, assim, um sistema, e ajustando-o frente à realidade (MOURA, 2003). No mapeamento da cidade de São João del-Rei, esse sistema foi adotado ao definir quais mapas gerar, quais as variáveis que os compõem e que servem de análise 
para identificar áreas propícias a perigos de deslizamentos de encostas, inundações e erosões.

A primeira etapa da pesquisa consistiu em levantamento de material cartográfico e dados secundários sobre a ocorrência de inundações. Os dados foram coletados em órgãos públicos, como o Instituto Brasileiro de Geografia e Estatística (IBGE), Prefeitura Municipal de São João del-Rei - MG, Defesa Civil Municipal, Comitê de Bacias do Estado de Minas Gerais e base digital e analógica de dados cartográficos do Departamento de Geociências da Universidade Federal de São João del-Rei.

O material cartográfico é composto por: uma carta topográfica elaborada pelo IBGE, no ano de 1971, escala de 1:50.000, equidistância de curvas de nível de 20 metros e imagem do satélite Landsat 8/OLI (Operation Land Imager) órbita/ponto 218/75, ano de 2015, resolução espacial 30 metros (bandas 4, 5 e 6) e 15 metros (banda pancromática). A elaboração da base digital de dados foi realizada pelo software ArcGis ${ }^{\circledR} 10.1$ (módulos ArcMap, ArcCatalog e ArcToolbox).

Inicialmente, realizou-se o georreferenciamento da Carta Topográfica na escala 1:50.000 na projeção Universal Transversa de Mercator (UTM) Datum Córrego Alegre, sendo posteriormente reprojetada para Datum da base South American Datum (SAD-69). Por meio da carta topográfica, foi vetorizado o limite da bacia hidrográfica, hidrografia, curvas de nível e pontos cotados. As curvas de nível e pontos cotados foram utilizados para elaborar o Modelo Numérico do Terreno (MNT) por interpolação pela ferramenta Create Tin, que transformou o MNT para o formato raster, por meio da ferramenta TIN to Raster, ambas disponibilizadas no Arcgis ${ }^{\circledR}$. O MNT no formato raster foi utilizado para elaborar o mapa de declividade. A hidrografia permitiu a elaboração de buffers em torno do Córrego do Lenheiro e seus afluentes.

A imagem de satélite Landsat 8/OLI foi recortada, reprojetada e, em seguida, foi aplicado o método de fusão de bandas, por meio da ferramenta Create Pan-Sharpened e Raster Dataset, ambas disponibilizadas no ArcGis. Posteriormente, a imagem foi vetorizada através de métodos de interpretação como tonalidade, textura, forma, padrão, sombra e tamanho, sendo possível gerar o mapa de uso da terra. A veracidade 
das informações foi validada em campo. O fluxograma (figura 1) ilustra os procedimentos metodológicos utilizados para a elaboração do mapeamento base.

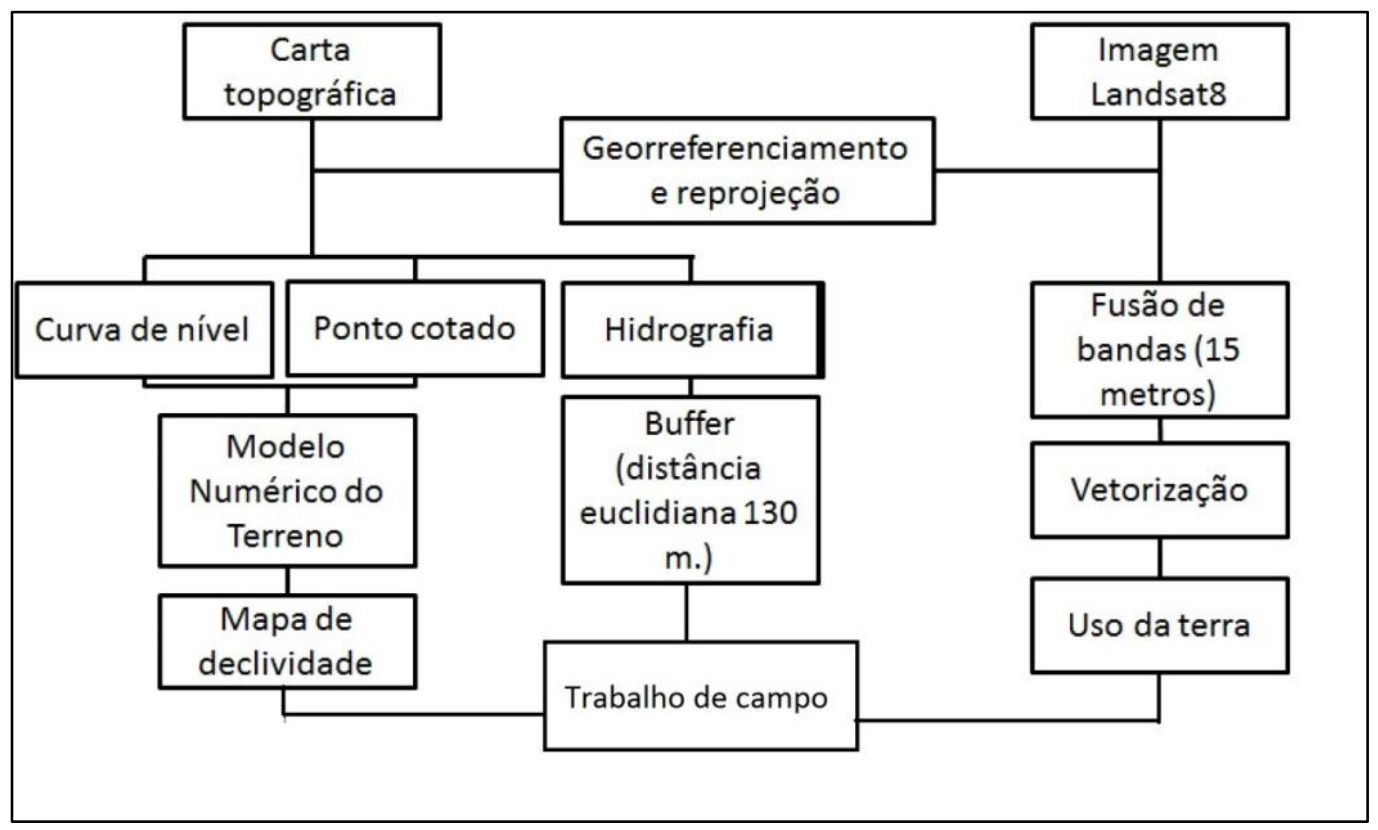

Figura 1 - Procedimentos metodológicos.

Por meio da análise multicriterial, foi elaborado o mapa síntese para áreas de enchentes e inundações na Bacia do Córrego do Lenheiro. Para a álgebra de mapas na análise multicriterial, a ferramenta utilizada foi a Weighted Overlay, que permite a inserção de pesos de 1 até o máximo 9, e influência de 100\% na soma de todos os mapas e comparação de dois a dois, conforme o método de AHP. Na tabela II, apresentam-se os mapas, pesos e as influências adotadas para a elaboração do modelo síntese.

Tabela II - Atribuição dos pesos e influências para as classes mapeadas.

\begin{tabular}{|l|l|l|l|}
\hline Variáveis & Influências & Classes & Pesos \\
\hline $\begin{array}{l}\text { Mapa } \\
\text { hipsométrico }\end{array}$ & $15 \%$ & 900 a 920 metros & 5 \\
\cline { 3 - 4 } & & 920 a 940 metros & 2 \\
\cline { 3 - 4 } & & 940 a 1220 metros & 1 \\
\hline
\end{tabular}




\begin{tabular}{|l|l|l|l|}
\hline $\begin{array}{l}\text { Mapa de } \\
\text { declividade }\end{array}$ & $35 \%$ & $0^{\circ} \mathrm{a} 5^{\circ}$ & 5 \\
\cline { 3 - 4 } & & $5^{\circ} \mathrm{a} 10^{\circ}$ & 3 \\
\cline { 3 - 4 } & $10^{\circ}$ a $65^{\circ}$ & 1 \\
\hline Uso da terra & $15 \%$ & Área urbana & 5 \\
\cline { 3 - 5 } & $\begin{array}{l}\text { Afloramento com vegetação nativa; Mata } \\
\text { ciliar; Pastagem; Solo exposto e } \\
\text { Vegetação rasteira. }\end{array}$ & 1 \\
\hline Buffer & $35 \%$ & 130 metros & 5 \\
\hline
\end{tabular}

Fonte: Elaborado pelos autores.

O procedimento consistiu na conversão dos mapas vetorizados em formato raster, com resolução espacial do pixel de 28 metros para todos os mapas; a adoção dos pesos de 1 a 5 para as classes de baixo a alto grau de suscetibilidade a enchentes respectivamente. A coleta de dados secundários incluiu os dados do PCPDC (DEFESA CIVIL, 2013, 2015), Atlas Brasileiro de Desastres Naturais - Volume Minas Gerais de 2011, as publicações de Pôssa e Ventorini (2014), Almeida et al. (2014), Almeida e Ventorini (2015), Santos, Ventorini e Almeida (2016) e do Brasil (2007), com ênfase na classificação dos graus de risco à inundação conforme mostra a tabela III.

Tabela III - Classificação dos graus de riscos.

\begin{tabular}{|l|l|}
\hline Graus de Risco & Descrição \\
\hline Baixo & $\begin{array}{l}\text { Sistema de drenagem com baixo potencial a causar danos e baixa frequência } \\
\text { de ocorrência (sem registros de ocorrências nos últimos } 5 \text { anos). }\end{array}$ \\
\hline Médio & $\begin{array}{l}\text { Sistema de drenagem com médio potencial a causar danos e média frequência } \\
\text { de ocorrência (uma ocorrência significativa nos últimos } 5 \text { anos). }\end{array}$ \\
\hline Alto & $\begin{array}{l}\text { Sistema de drenagem com médio potencial a causar danos e média frequência } \\
\text { de ocorrência (uma ocorrência significativa nos últimos } 5 \text { anos), envolvendo } \\
\text { moradias de alta vulnerabilidade. }\end{array}$ \\
\hline Muito alto & $\begin{array}{l}\text { Sistema de drenagem com alto potencial a causar danos e alta frequência de } \\
\text { ocorrência (pelo menos três ocorrências significativas nos últimos } 5 \text { anos), } \\
\text { envolvendo moradias de alta vulnerabilidade. }\end{array}$ \\
\hline
\end{tabular}

Fonte: Ministério das Cidades (2007, p. 109). 
Para verificar a veracidade das informações mapeadas, foram realizados nove trabalhos de campo nos períodos chuvosos, secos e intermediários, entre os anos de 2013 e 2015. Em campo, foram realizados registros fotográficos e a identificação de áreas suscetíveis a enchentes e inundações. Para validar o modelo de síntese de áreas suscetíveis a enchentes e alagamentos, foram analisados os dados desses desastres disponibilizados pela Defesa Civil do município, assim como os dados coletados por meio de um questionário com 12 questões objetivas, que buscam responder alguns pontos como: se sua casa está localizada em uma área de risco de enchente e/ou inundação, se houve ocorrência de algum desses tipos de desastres na residência do entrevistado, ou até mesmo, se o entrevistado já observou algum desastre em seu bairro, dentre outras. As perguntas foram respondidas por 24 moradores residentes ao longo das margens do Córrego do Lenheiro.

\section{Resultados e análises}

O mapa hipsométrico (figura 2) aponta amplitude altimétrica de 300 metros, no qual parte significativa da área urbana na bacia se encontra nas menores altitudes (entre 900 a 940 metros). As cotas mais elevadas estão localizadas na Serra do Lenheiro, divisor de águas da bacia. A proximidade com o núcleo principal impulsionou a urbanização para as áreas próximas das cotas mais elevadas (entre 980 a 1020 metros). 


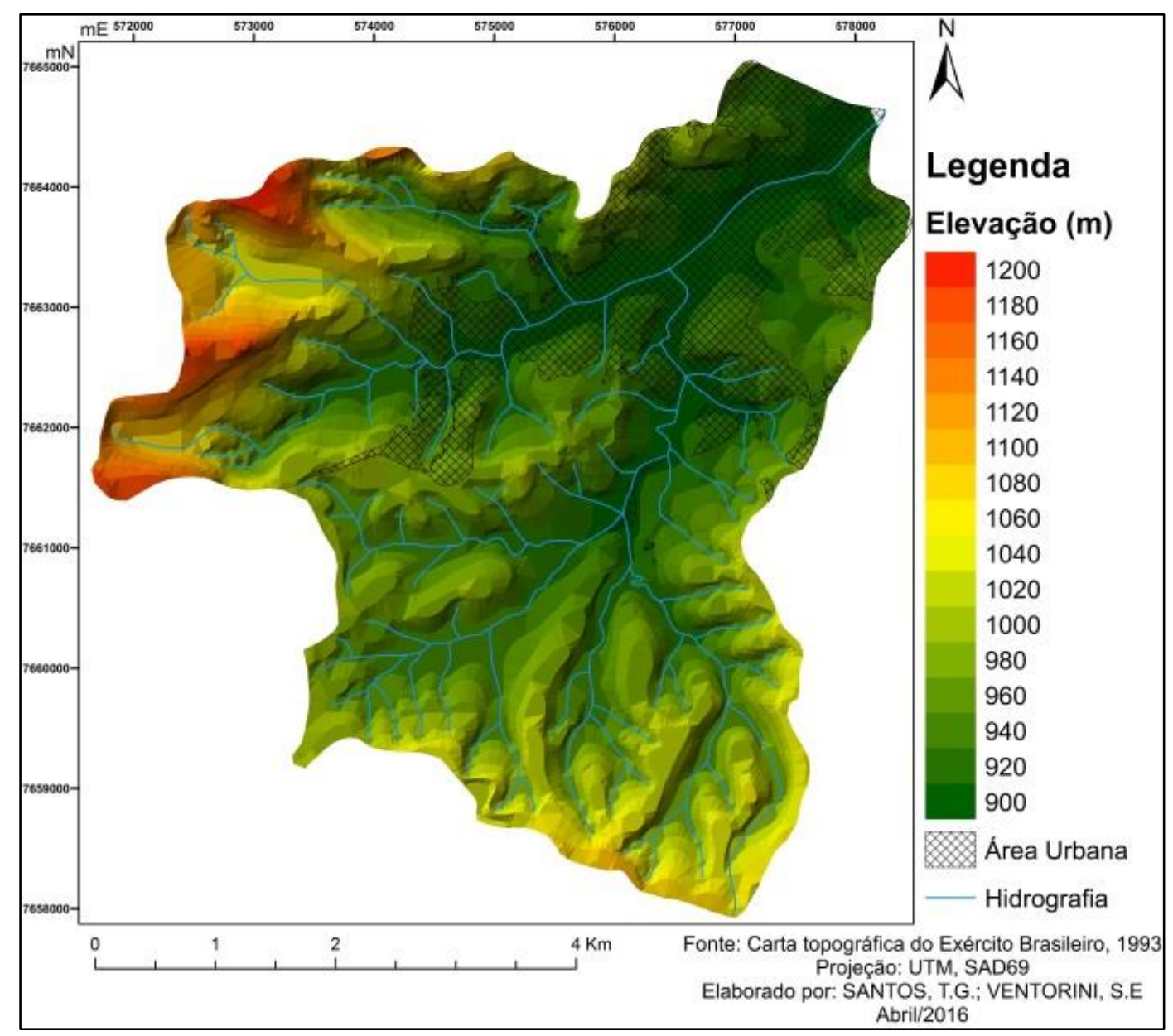

Figura 2 - Mapa hipsométrico da Bacia do Córrego do Lenheiro, São João del-Rei - MG.

O mapa de declividade (figura 3) indica áreas com declividades elevadas próximas ao divisor de águas da bacia, caracterizadas por um relevo íngreme. A área urbana corresponde à declividade entre $2^{\circ}$ e $10^{\circ}$, e representa um relevo plano e com ondulações suaves. As declividades entre $2^{\circ}$ e $5^{\circ}$ caracterizam escoamento superficial lento e contribuem para a ocorrência de enchentes e inundações, o que coloca em risco os moradores que vivem às margens do Córrego do Lenheiro. Observa-se a ocupação urbana em áreas com declividades mais elevadas $\left(25^{\circ}\right.$ a $\left.50^{\circ}\right)$, em direção à Serra do Lenheiro. 


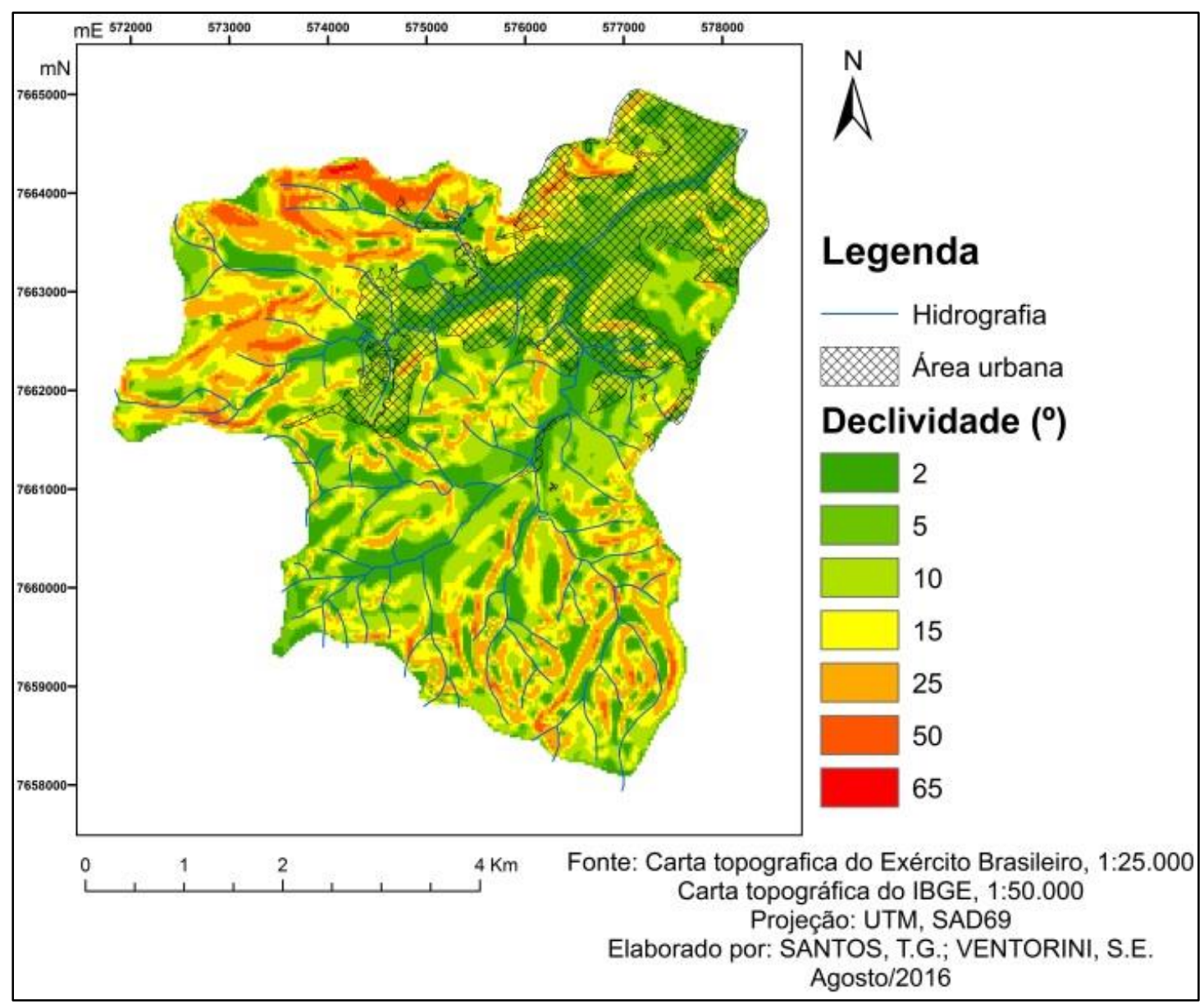

Figura 3 - Mapa de declividade da Bacia do Córrego do Lenheiro, São João del-Rei - MG.

O mapa de uso da terra (figura 4) aponta a ausência de mata ciliar ao longo do Córrego do Lenheiro, áreas significativas de vegetação rasteira na porção Sul e Sudeste e pastagem na porção Centro-Oeste. Na porção Noroeste, encontram-se as áreas de afloramento com vegetação, onde está inserida a Serra do Lenheiro, e no entorno da área urbana estão inseridas as áreas de plantação e de solo exposto. Os buffers indicam a distância euclidiana de 80 metros em relação aos cursos hidrográficos e corresponde às áreas atingidas pelos desastres humanos de natureza, de acordo com o PCPDC (DEFESA CIVIL, 2015), e de 50 metros em relação ao primeiro, tendo como distância euclidiana total 130 metros. 


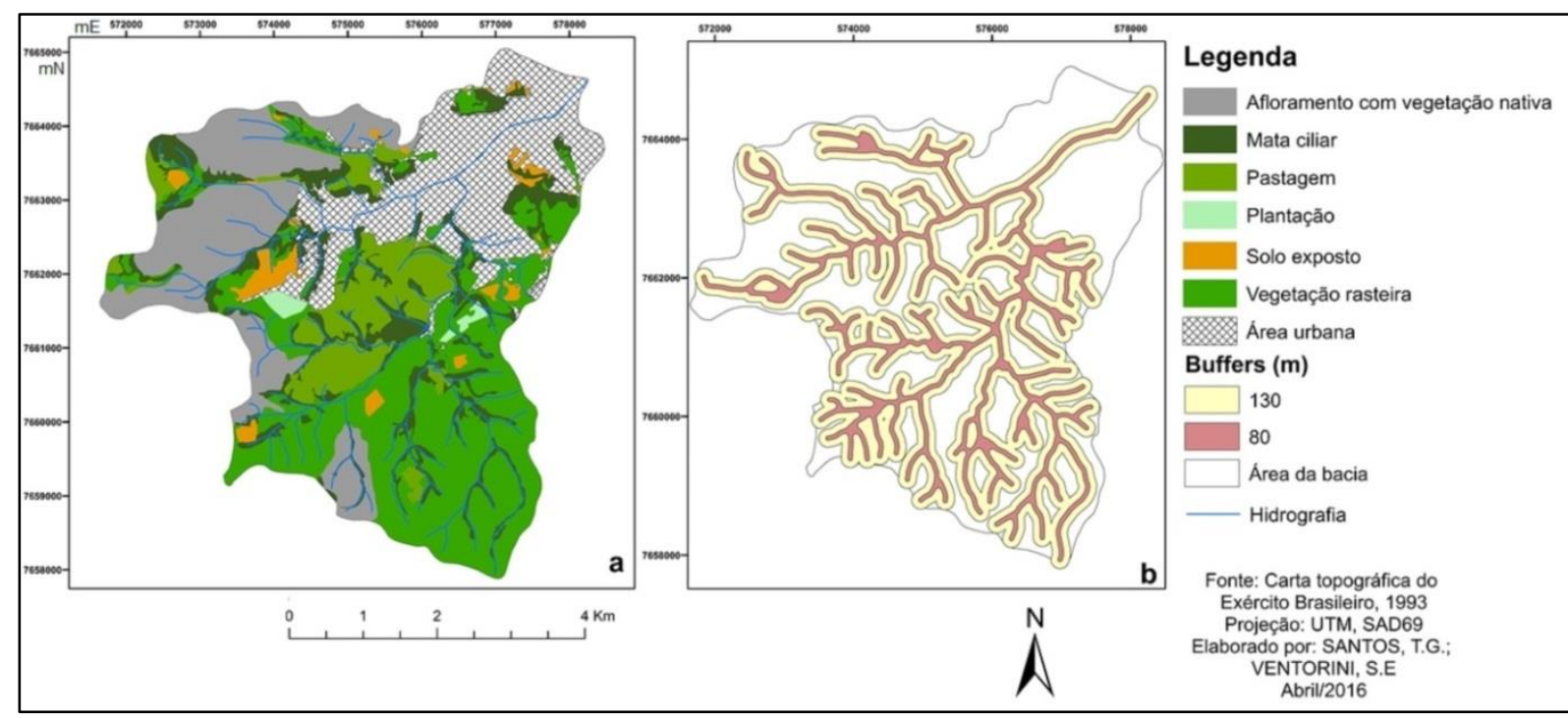

Figura 4 - Mapas do uso da terra (a) e buffers (b) da Bacia do Córrego do Lenheiro, São João delRei - MG.

Por meio da técnica da análise multicritério, foi realizada a álgebra dos mapas hipsométrico, declividade, uso da terra e buffers, resultando em um modelo-síntese das áreas com potencial para ocorrência de enchentes e inundações. A legenda obtida na escala de 1 a 5 correspondem: "1 - Muito baixo"; "2 - Baixo"; "3 - Médio"; "4 - Forte" e " 5 - Muito forte" à suscetibilidade de ocorrências de enchentes e alagamentos (figuras 5 e 6).

O ponto A, destacado na figura 6 , corresponde à região do Bairro Tejuco, na área de confluência do Córrego do Lenheiro com o Córrego do Rio Acima. O processo de ocupação irregular das áreas de várzea do Córrego do Lenheiro e o descarte incorreto de resíduos nos rios potencializam os desastres humanos de natureza. O PCPDC ressalta que o Córrego do Lenheiro atua como barragem do Córrego do Rio Acima; assim, o segundo ao encontrar-se com o primeiro, extravasa o nível das águas em seu canal fluvial, e agrava as inundações neste ponto. O nível das águas neste ponto varia de um a dois metros nas residências.

O ponto $\mathrm{B}$, da figura 6, representa a região do bairro Fábricas, próximo à Avenida Leite de Castro, uma das principais vias de acesso entre os extremos da cidade. As áreas de várzea foram densamente ocupadas e, assim como no ponto A, o descarte incorreto 
Mapeamento digital das áreas propícias às enchentes e inundações na bacia do Córrego do Lenheiro em São João del-Rei - MG

Thiago Gonçalves Santos, Sílvia Elena Ventorini

de resíduos sólidos potencializa os fenômenos. Segundo o PCPDC, o nível das águas pode chegar a pouco mais de um metro dentro das residências (SÃO JOÃO DEL REI. DEFESA CIVIL, 2015). 


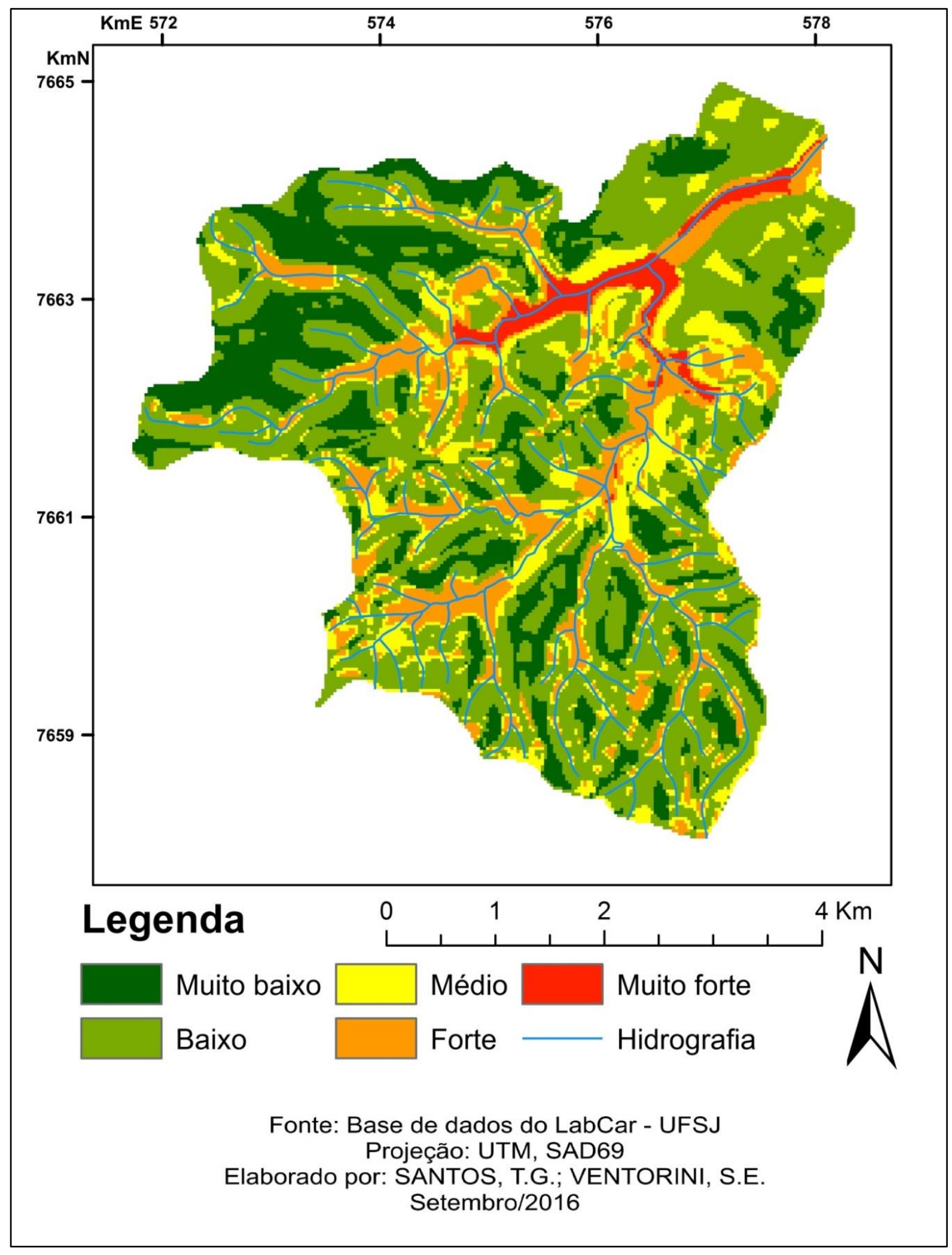

Figura 5 - Mapa síntese das áreas suscetíveis às enchentes e inundações da Bacia do Córrego do Lenheiro, São João del-Rei - MG. 


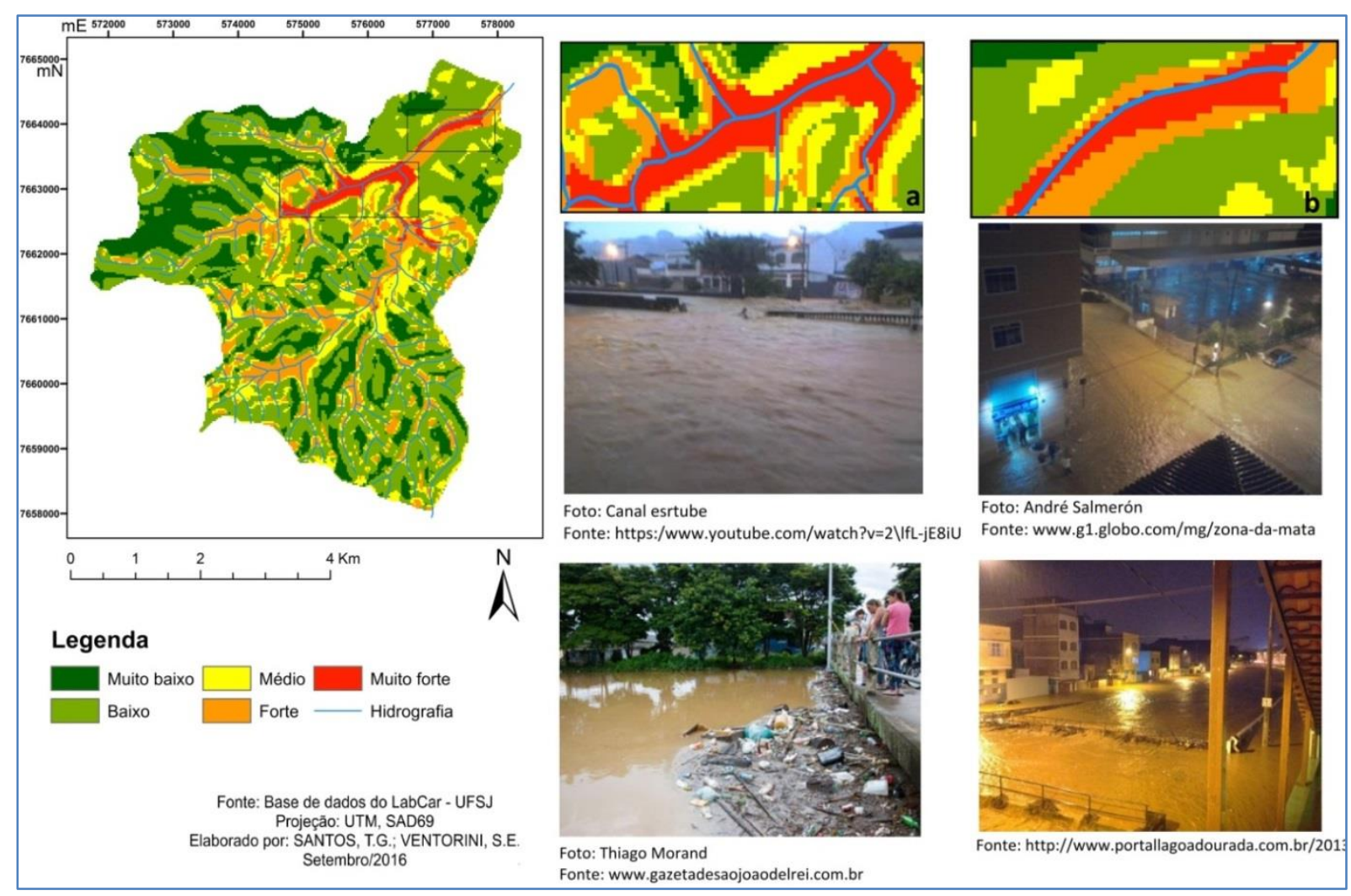

Figura 6 - Mapa síntese das áreas suscetíveis as enchentes e inundações da Bacia do Córrego do Lenheiro, São João del-Rei - MG: Pontos (a) e (b) áreas suscetíveis.

O PCPDC (SÃO JOÃO DEL REI. DEFESA CIVIL, 2015) indica registros atualizados de enchentes e inundações na bacia do Córrego do Lenheiro, nos anos de 2001, 2004, 2007, 2012 e 2013. No período chuvoso de 2011/2012, as precipitações atingiram o município de São João del-Rei, e causaram prejuízos econômicos e sociais, em decorrência dos desastres humanos de natureza - enchentes, inundações e deslizamentos -, a partir dos quais 2.218 pessoas foram afetadas e duas ficaram desabrigadas. Além disso, houve a danificação de estradas, pontes, imóveis comerciais, redes de distribuição de água e de captação de esgoto.

O prejuízo econômico estimado é de $\mathrm{R} \$ 2.780 .865,00$. Já no período chuvoso de 2013/2014, 1.500 pessoas foram atingidas pelas enchentes e inundações no município. Vias públicas e muros às margens do Córrego do Lenheiro foram danificados, e os prejuízos econômicos foram estimados no valor de $\mathrm{R} \$ 170.868,36$. Os dados citados confirmam a 
veracidade do mapa síntese das áreas vulneráveis às enchentes e inundações na Bacia do Córrego do Lenheiro (SÃO JOÃO DEL REI. DEFESA CIVIL, 2015).

Os registros do PCPDC, somados à classificação do grau de risco de inundação proposta pelo Ministério das Cidades, validam os resultados obtidos do mapa síntese da figura 5. As áreas destacadas como muito forte foram validadas com os dados da Defesa Civil e as entrevistas em campo. A validação indicou que a área corresponde aos atingidos no período chuvoso de 2011/2012 e 2013/2014.

Os dados coletados em campo indicam a impermeabilização das margens do Córrego do Lenheiro e de seus afluentes; este fato se dá por meio do adensamento populacional. Nota-se a ocupação de mais de uma família no mesmo lote, no qual a mesma infraestrutura de saneamento básico é compartilhada entre os moradores. Neste caso, é característico da área padrões de moradia conhecidos popularmente como "puxadinhos".

Os dados coletados pelo questionário mostram que 50\% dos entrevistados (12 pessoas) constituem 29\% (sete pessoas) em área de enchentes e 21\% (cinco pessoas) em uma área sem riscos de ocorrências de enchentes e/ou inundações. No entanto, durante as entrevistas, constatou-se que a população adquire a noção dos riscos existentes em relação às enchentes e alagamentos somente quando há danos materiais, como mostra a resposta de um morador: "Minha casa está em uma área normal, na última chuva entrou água só na garagem, dentro de casa isso nunca aconteceu". Por não ocorrerem prejuízos sociais e econômicos, o morador desconsidera que sua residência está em uma área de risco de alagamento.

Todos os entrevistados (24 pessoas) já observaram ocorrências de enchentes e/ou inundações ocasionadas pela extrapolação do nível das águas no canal fluvial do Córrego do Lenheiro. Desta forma, os dados coletados por meio do questionário validam o modelo de síntese. 


\section{Conclusões}

Historicamente, as margens do Córrego do Lenheiro tiveram ocupações motivadas pela exploração aurífera, ocorrida no século XVII, e se mantêm até hoje (MALDOS, 2000). Este fato ocorre pela proximidade da área com a zona central e com setores importantes do município. No Brasil, embora existam leis que determinem a elaboração do mapeamento de áreas de risco, como o auxílio no planejamento e gestão, parte dos municípios brasileiros possui um mapeamento precário, sem critérios técnicos e/ou científicos.

Uma base digital de dados permite a elaboração de mapas temáticos que subsidiam os órgãos públicos a tomarem medidas mitigadoras para a redução de ocorrências dos desastres humanos de natureza, como as enchentes e inundações. A análise multicritério é um método que auxilia a tomada de decisão por parte do pesquisador e a análise de fenômenos específicos de cada objeto de estudo. A etapa da adoção de pesos referentes à AHP corresponde ao processo em que se avalia o grau de importância das variáveis e suas classes. O resultado obtido pela técnica representada foi validado pelos dados disponibilizados pela Defesa Civil do Município e por dados coletados em campo.

A ocupação inadequada das áreas de várzea, a impermeabilização do solo, o descarte incorreto de resíduos sólidos, bem como a precária rede de drenagem e sanitária são fatores recorrentes da atividade humana que contribuem para a ocorrência de enchentes e inundações, além de gerarem prejuízos econômicos e sociais aos moradores. Além disso, às margens dos córregos, os moradores convivem com o mau cheiro, presenciam insetos e/ou roedores e ficam propensos ao risco de contaminação pelo contato com as águas.

O mapeamento de áreas com graus distintos de probabilidades de ocorrências dos desastres auxilia na tomada de medidas mitigadoras para diminuir os ricos de prejuízos socias e econômicos na área. Como já descartado, os municípios brasileiros enfrentam dificuldades relacionadas à ausência de recursos humanos, equipamentos e documentos cartográficos de base para mapear aspectos naturais e antrópicos de seus territórios. Na 
pesquisa, o desafio foi elaborar o mapeamento das áreas suscetíveis aos Desastres Humanos de Natureza na Bacia do Córrego do Lenheiro.

Concluímos que o objetivo proposto para a pesquisa foi alcançado, e o mapeamento contribuirá para amenizar a escassez de documentos cartográficos como apoio à gestão e planejamento de áreas suscetíveis a ocorrências de enchentes e inundações na Bacia.

\section{Referências}

ALBUQUERQUE, Sabrina Moreira de. Modelagem de alternativas de traçado de ferrovias com uso de ferramentas de SIG e parâmetros geoambientais. 2015. 173 f. Dissertação (Mestrado) - Universidade de Brasília, Curso de Pós Graduação em Geociências Aplicadas, Brasilia, 2015.

ALMEIDA. Claudia Maria de. O dialogo entre as dimensões real e virtual urbano. In ALMEIDA, Claudia Maria de; CÂMARA, Gilberto; MONTEIRO, Antônio Miguel Vieira (Orgs.) Geoinformação em urbanismo: cidade real x cidade virtual. São Paulo: Oficina de Texto, 2007

ALMEIDA, Gustavo Pyra; VENTORINI, Silvia Elena. Mapeamento participativo de áreas de risco a movimento de massa no bairro Senhor dos Montes - São João del-Rei, MG.

Caderno de Geografia, Belo Horizonte, v. 24, n. 1, p.79-93, 1 jun. 2014. Disponível em: <http://periodicos.pucminas.br/index.php/geografia/issue/archive>. Acesso em: 17 fev. 2015.

ARROYO, José Elias Claudio. Heurísticas e metaheurísticas para otimização combinatória multiobjetivo. 2002. 232 f. Tese (Doutorado) - Universidade Estadual de Campinas, Curso de Engenharia Elétrica e de Computação, Campinas, 2002. Disponível em: <http://www.bibliotecadigital.unicamp.br/document/?code=vtls000256530\&fd=y>. Acesso em: 09 maio 2017.

AUMOND, Juarês José; LOCH, Carlos; COMIN, Jucinei José. Abordagem sistêmica e o uso de modelos para recuperação de áreas degradadas. Revista Árvore, Viçosa, v. 36, n. 6, p.1099-1118, 04 jun. 2012.

BONHAM-CARTER, Graeme. Geographic information systems for geoscientists: Modelling with GIS. New York: Elsevier, 1994. 416 p. 
BRASIL. INSTITUTO DE PESQUISA TECNOLÓGICA. Mapeamento de riscos em encostas e margens de rios. Brasilia: Ministério das Cidades, 2007. $176 \mathrm{p}$.

BRASIL. Lei n 9433, de 9 de janeiro de 1997. Lei da Política Nacional de Recursos Hídricos. Brasília, 1997. Disponível em: <http://www.planalto.gov.br/ccivil_03/leis/L9433.htm>. Acesso em: 22 jun. 2016.

BRASIL. Lei n 9984, de 9 de julho de 2000. Criação da Agência Nacional das Águas - Ana. Brasília, 2000. Disponível em: <http://www.planalto.gov.br/ccivil_03/leis/L9984.htm>. Acesso em: 22 jun. 2016

BRASIL. Lei $n^{\circ}$ 12608, de 10 de abril de 2012. Política Nacional de Proteção e Defesa Civil Pnpdec. Brasília, 2012. Disponível em: <http://www.planalto.gov.br/ccivil_03/_Ato20112014/2012/Lei/L12608.htm>. Acesso em: 22 jun. 2016.

CABRAL, Adilson Vaz. Análise multicritério em sistemas de informação geográfica para a localização de aterros sanitários: o caso da região sul da ilha de Santiago, Cabo Verde. 2012. 100 f. Dissertação (Mestrado) - Curso de Geografia, Faculdade de Ciências Sociais e Humanas, Lisboa, 2012.

CAMPOS, Maria Betânia Aparecida. Métodos multicritérios que envolvem a tomada de decisão. 2011. 51 f. Monografia (Especialização) - Universidade Federal de Minas Gerais, Curso de Especialização em Matemática, Belo Horizonte, 2011.

CARMO, Roberto Luiz do; ANAZAWA, Tathiane Mayumi. Mortalidade por desastres no Brasil: o que mostram os dados. Ciência \& Saúde Coletiva, Rio de Janeiro, v. 9, n. 19, p.3669-3681, jun. 2014. Disponível em: <http://www.scielo.br/ >. Acesso em: 08 fev. 2014.

CASTRO, Antônio Luiz Coimbra. Glossário de defesa civil: estudo de riscos e medicina de desastres. Brasília: MPO/ Departamento de Defesa Civil, 1998. 283 p.

CASTRO, Susana D. Aneas de. Riesgos y peligros: una visión desde la geografía. Geografía y Ciencias Sociales, Universidad de Barcelona, n. 60, p.1-15, 15 mar., 2000.

CENTRO UNIVERSITÁRIO DE ESTUDOS E PESQUISAS SOBRE DESASTRES. Atlas brasileiro de desastres naturais 1991 a 2010: volume Minas Gerais. Florianópolis: CEPED/UFSC, 2011, $95 \mathrm{p}$.

CHRISTOFOLETTI, Antônio. A aplicação da abordagem em sistema na geografia física. Revista Brasileira de Geografia, Rio de Janeiro, v. 2, n. 52, p.21-35, jun. 1990.

CHRISTOFOLETTI, Antônio. Análise de sistemas em Geografia. São Paulo: Hucitec/Edusp. 1979 
CHORLEY, Richard J.; HAGGETT, Peter. Integrated models in geography. New York: Routledge Revivals, 1967. $667 \mathrm{p}$.

CODAR, Codificação de desastres, ameaças e riscos: sistemática de codificação. Brasília: Diário Oficial, n. 4.5 jan. $1995,1995$.

FERNANDEZ, Ocar Vicente Quinonez. Determinação do nível e das descargas de margem plena em cursos fluviais. Boletim de Geografia. n.21, v. 1, p 97-109, 2003.

FIDALGO, Elaine Cristina Cardoso. Critérios para a análise de métodos e indicadores ambientais usados na etapa de diagnóstico de planejamentos ambientais. 2003. $258 \mathrm{f}$. Tese (Doutorado) - Curso de Engenharia Agrícola, na área de Concentração em Planejamento e Desenvolvimento Rural Sustentável., Universidade Estadual de Campinas, Campinas, 2003. Disponível em:

<http://www.repositorio.unicamp.br/bitstream/REPOSIP/257634/1/Fidalgo_ElaineCristinaC ardoso_D.pdf>. Acesso em: 21 jun. 2017.

GRASSI, Jean et al. Mapeamento da vulnerabilidade a inundações e deslizamentos de terra no Estado do Paraná. In: SIMPÓSIO BRASILEIRO DE SENSORIAMENTO REMOTO, 2013, Foz do Iguaçu (PR). Anais... . Foz do Iguaçu: Inpe, 2013. p. 2501-2508. Disponível em: <http://www.dsr.inpe.br/sbsr2013/files/p0608.pdf>. Acesso em: 07 set. 2016.

HORA, Silmara Borges da; GOMES, Ronaldo Lima. Mapeamento e avaliação do risco a inundação do Rio Cachoeira em trecho da área urbana do município de Itabuna/BA. Sociedade \& Natureza, Uberlândia, v. 2, n. 21, p.57-75, ago. 2009. Disponível em: <http://www.scielo.br/pdf/sn/v21n2/a05v21n2.pdf>. Acesso em: 01 set. 2016

INTERNATIONAL STRATEGY FOR DISASTER REDUCTION. Living with risk: a global review of disaster reduction initiatives. New York And Geneva: United Nations, 2004. 127 p. Disponível em: <http://www.unisdr.org/we/inform/publications/657>. Acesso em: 11 fev. 2015.

KOBIYAMA, Masato et al. Prevenção de desastres naturais: conceitos básicos. Florianópolis: Editora Organic Trading, 2006. 109 p. Disponível em: <http://www.ambiente.sp.gov.br/proclima/files/2014/05/prevencaodedesastresnaturaisco nceitosbasicos1.pdf>. Acesso em: 12 fev. 2015.

\section{LINDELL, Michael K.; PRATER, Carla S.; PERRY, Ronald W. Fundamentals of emergency} management. Emmitsburg: Emergency Management Institute, 2006. [479 p.]. Disponível em: <http://training.fema.gov/hiedu/aemrc/booksdownload/fem/>. Acesso em: 13 fev. 2015. 
MALDOS, Roberto. A formação urbana da cidade de São João del-Rei. 2000. Disponível em: <http://www.saojoaodelreitransparente.com.br/works/view/605> Acesso em: 15 de janeiro 2013.

MOURA, Ana Clara Mourão. Reflexões metodológicas como subsídio para estudos ambientais baseados em Análise de Multicritérios. In: SIMPÓSIO BRASILEIRO DE SENSORIAMENTO REMOTO, XIII, Florianópolis, Brasil, 21-26 abril 2007. Anais..., São José dos Campos: INPE, 2007.

MOURA, Ana Clara Mourão. Learning Topics in Urban Planning at UFMG: Geoprocessing to Support Analysis, Planning and Proposal of the Urban Landscape at Neighborhood Scale. In. SEMINÁRIO INTERNACIONAL DE PLANEJAMENTO E GESTÃO AMBIENTAL URBENVIRON, $5^{\circ}$, Brasília 2012. Anais... Brasília: Urbenviron, 2012. Tema do evento: Respostas Urbanas às Mudanças Climáticas Paranoá

MOURA, Ana Clara Mourão; JANKOWSKI, Piotr. Contribuições aos estudos de análises de incertezas Como complementação às análises multicritérios - "sensitivity analysis to suitability evaluation”. Revista Brasileira de Cartografia: Edição Especial Geoinformação e Análise Espacial, Rio de Janeiro, v. 4, n. 68, p.665-684, abr. 2016. Disponível em: <http://geoproea.arq.ufmg.br/+/dmFront/downloadContent?u=eyJtZWRpVV9pZCI6ljU2Nil sInRpbWVzdGFtcCI6MTQ4NDgzODEzMHo=>. Acesso em: 19 jan. 2017

NUNES, Lucí Hidalgo. Urbanização e desastres naturais: abrangência América do Sul. São Paulo: Oficina de Texto, 2015.

PEIXOTO, Maria Naíse de Oliveira; RIO, Gisela Pires do. Riscos ambientais e geografia: conceituações, abordagens e escalas. Anuário do Instituto de Geociências da UFRJ, Rio de Janeiro, v. 28, n. 2, p. 11-30, 2005. Disponível em:

<http://www.anuario.igeo.ufrj.br/anuario_2005/Anuario_2005_11_30.pdf> Acesso em 21 de ago

PÔSSA, Évelyn Márcia; VENTORINI, Silvia Elena. Diagnóstico geoambiental: mapeamento digital da bacia do córrego do Julio São João del-Rei - MG. IN: ENCUENTRO DE GEÓGRAFOS DE AMÉRICA LATINA, 2013, Lima- Peru. Anais... Local: Editor, 2013. p. 1-20. Tema do evento: Reencuentro de saberes territoriales latinoamericanos

SANTOS, Thiago Gonçalves; VENTORINI, Silvia Elena. ; ALMEIDA, Gustavo Pyra. Mapeamento de áreas suscetiveis a ocorrencia de enchentes e inundações na Bacia Do Córrego Do Lenheiro. In: Giovanni Seabra. (Org.). Terra paisagens, solos, biodiversidade e os desafios para um bom viver. 1. ed. Ituiutaba: Barlavento, 2016, v. 1, p. 1331-1341

SÃO JOÃO DEL-REI . DEFESA CIVIL. Plano de contingência de proteção e defesa civil. São João del-Rei, 2015, 159 p. 
SÃO JOÃO DEL-REI . DEFESA CIVIL. Plano de contingência de proteção e defesa civil. São João del-Rei, 2013, 94 p.

SÃO PAULO. INSTITUTO DE PESQUISAS TECNOLÓGICAS. Cartas de suscetibilidade a movimentos gravitacionais de massas e inundações - 1:25.000. Brasília: Cprm - Serviço Geológico do Brasil, 2014. 44 p. Disponível em:

<http://rigeo.cprm.gov.br/xmlui/bitstream/handle/doc/16588/NT-

Carta_Suscetibilidade.pdf?sequence=1>. Acesso em: 09 maio 2017.

SOUZA, Tissiana Almeida; CUNHA, Cenira Maria Lupinacci. Análise dos atributos físicoambientais do município de Praia Grande-SP. Sociedade \& Natureza, Uberlândia, v. 2, n. 24, p.303-318, 11 set. 2012.

STAAY, Thomas Lorie. Decision making with the analytic hierarchy process. Pittsburgh: Int. J. Services Sciences, 2008 , p. 83-98. Disponível em:

<http://www.colorado.edu/geography/leyk/geog_5113/readings/saaty_2008.pdf >. Acesso em: 02 set. 2016.

TOMINAGA, Lídia Keiko. Desastres naturais: por que ocorrem? In. TOMINAGA, Lídia Keiko; SANTORO, Jair; AMARAL, Rosangela (Orgs.). Desastres Naturais: conhecer para prevenir. São Paulo: Instituto Geológico, 2009. Disponível em: <http://www.igeologico.sp.gov.br/downloads

TROPPMAIR, Helmut. Sistemas, geossistemas, geossistemas paulista, ecologia da paisagem. Rio Claro, 2004. 128 p.

TROPPMAIR, Helmut. Geossistemas. Mercator: Revista de Geografia da Universidade Federal do Ceará, v. 5, n. 10, p.79-89, 2006.

TUCCI, Carlos Eduardo Morelli. Inundações urbanas na América do Sul In. TUCCI, Carlos Eduardo Morelli; BERTONI, Juan Carlos. (Orgs.). Inundações urbanas na América do Sul. Porto Alegre: Associação Brasileira de Recursos Hídricos - Abrh, 2003. 150 p. Disponível em: <http://www.cepal.org/samtac/noticias/documentosdetrabajo/5/23335/inbro2803.pdf>. Acesso em: 16 abr. 2016.

TUCCI, Carlos Eduardo Morelli; BERTONI, Juan Carlos. (Orgs.). Inundações urbanas na América do Sul. Porto Alegre: Associação Brasileira de Recursos Hídricos - Abrh, 2003. 150 p. Disponível em:

<http://www.cepal.org/samtac/noticias/documentosdetrabajo/5/23335/inbro2803.pdf>. Acesso em: 16 abr. 2016. 
UITTO, Juha Ilari. The geography of disaster vulnerability in megacities: a theoretical framework. Applied Geography, Great Britain, v. 18, n. 1, p.7-16, jun. 1998.

VALENTE, Roberta de Oliveira Averna. Definição de áreas prioritárias para conservação e preservação florestal por meio da abordagem multicriterial em ambiente SIG. 2005. Tese (Doutorado em Recursos Florestais) - Escola Superior de Agricultura Luiz de Queiroz, Universidade de São Paulo, Piracicaba, 2005. doi:10.11606/T.11.2005.tde-15062005-154402. Acesso em: 2017-06-21.

WISNER, Ben et al. At risk: natural hazards, people's vulnerability and disasters. 2. ed. New York: La Red (latin America), Duryog Nivaran (south Asia) And Peri-peri (southern Africa), 2003.124 p. Disponível em: <http://www.preventionweb.net/files/670_72351.pdf>. Acesso em: 10 fev. 2015

ZACHARIAS, Andrea Aparecida. A representação gráfica das unidades de paisagem no zoneamento ambiental. São Paulo: Editora Unesp, 2007. 211 p.sto de 2014. 